\title{
Local evidenced-based policy options to improve food security in South Australia: the use of local knowledge in policy development
}

\author{
Amber Bastian* and John Coveney \\ School of Medicine, Flinders University, GPO Box 2100, Adelaide, SA 5001, Australia
}

Submitted 2 June 2011: Accepted 9 November 2011: First published online 14 December 2011

\begin{abstract}
Objective: To examine realist policy options for the South Australian government to improve food security.

Design: Semi-structured interviews with twenty-four key South Australian food security stakeholders.

Setting: Food security is a global issue that affects both developing and developed countries. Governments are well placed to improve food security but the solutions are not always evident.

Subjects: Policy makers, leaders of non-government organisations, private enterprise and front-line food security workers in South Australia.

Results: The research produced forty-four potential policy options for the South Australian government to improve food security.

Conclusions: Stakeholders offered detailed policy solutions for the local context. This illustrates how gathering local evidence expands understanding on an issue. The process used to generate these policy options is applicable to other public health problems and other contexts.
\end{abstract}

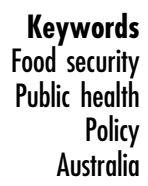

Food security refers to the ability of individuals, households and communities to acquire appropriate and nutritious food on a regular and reliable basis using socially acceptable means. It is determined by both the food supply and people's ability to access and use food. Food insecurity refers to any of the following: (i) not having sufficient food; (ii) experiencing hunger as a result of running out of food; (iii) eating a poor-quality diet as a result of limited food options and access; (iv) anxiety about acquiring food; or (v) having to rely on food relief ${ }^{(1)}$. Food security is an important public health issue both globally and locally. As food insecurity impacts on nutritional intake it can contribute to a number of diet-related diseases. Chronic disease risk and incidence, adult obesity (especially in women), HIV infection, diminished cognitive performance, academic achievement and behaviour problems in children have all been associated with food insecurity in developed countries ${ }^{(2-9)}$. In South Australia an average of $5 \cdot 6 \%$ of survey respondents aged over 16 years reported to have run out of food and could not afford to buy more' between July 2002 and December 2006 ${ }^{(10)}$. However, the real number experiencing food insecurity is likely to be more as individuals of highest risk such as homeless people and people with mental health, drug and alcohol problems can be missed by population health surveys ${ }^{(11)}$. Despite the recognition that food security is an important public health issue, there remains a gap in the evidence base both internationally and locally on the most effective policy options to improve it. With the move towards evidence-based policy, public health policy makers may turn to systematic reviews of the literature to uncover sound evidence on what works and which types of solutions provide the best value for money. However, this approach often overlooks the impact of local context on the success of interventions. Pawson proposes a 'realist' approach to the synthesis of evidence to overcome this challenge. This methodology considers the local contexts of interventions to uncover what types of strategies will work for which people in what kinds of settings or 'what works for whom in what circumstances, ${ }^{(12)}$. With the lack of evidence and evaluation on what specific policy options should be implemented to address food insecurity generally, and in South Australia particularly, policy makers need to be flexible in types of evidence they use. Target populations and stakeholders provide their own forms of evidence (knowledge, experience, ideas and opinions) that interact with research evidence ${ }^{(13)}$. Consultation with these groups can provide insight into the feasibility of implementing certain policy options and strategies and thus increase their effectiveness ${ }^{(14,15)}$.

The research presented in the current paper explores key stakeholders' perceptions on food security within 
South Australia and forms part of a larger study with the overarching aim to identify local evidence-based policy options for the South Australian state government to improve food security. The findings presented here relate directly to the research question 'what do key stakeholders think are the realistic policy options to improve food security within South Australia?' For the purpose of the current research the term 'key stakeholders' refers to stakeholders who have potential to impact food security through changing the food supply or through influencing social and economic determinants of health and thereby people's access to food. 'Realistic policy options' refer to interventions and strategies that have potential to improve food security and are deemed feasible within the context (considering political, economic, social and cultural factors) of South Australia.

\section{Method}

The current research takes a constructionist perspective with the underlying assumption that the success of policy solutions is dependent on the local context in which they are to be implemented. It is based on underlying principles of grounded theory methodology, where outcomes of the research are fed back into the research as it progresses and in doing so help shape and form the research design ${ }^{(16)}$. Before gathering and analysing stakeholders' views on food security a systematic literature review was conducted for the past decade to uncover various ways food security is spoken about within the academic literature and emerging themes on determinants and potential policy solutions. Using a grounded theory approach the literature review findings helped make sense of the interview findings as they emerged, rather than the literature determining a set of evidence-based policy options which participants were asked to prioritise or choose from. This helped expand vision rather than constrict it and allowed for local evidence (knowledge, experience, ideas and opinions of key stakeholders) to be truly valued through influencing the study design $^{(12)}$. Similarly, participants were asked to identify other potential stakeholders for interview throughout the study. This snowball sampling was chosen so that study participants could use their local knowledge to help shape research design. As the project progressed findings from earlier interviews were fed into subsequent interviews to test the acceptability of proposed solutions. By using this approach data from earlier interviews not only influenced who was interviewed at a later stage but also the types of questions they were asked. Any new emerging themes and stakeholders were noted as the study progressed. The recruitment of participants was concluded once no new stakeholders or themes emerged (had reached a point of saturation).

Semi-structured interviews were conducted with twenty-four key stakeholders currently involved in food security or with the potential to improve food security within South Australia. Ethics approval was sought and obtained from Flinders University social and behaviour research ethics committee. Participants were sent a discussion paper on food security which formed the basis for key questions asked during the semi-structured interviews. Voice recordings of interviews were transcribed verbatim to allow for detailed analysis ${ }^{(17)}$. Interview transcripts were then rechecked against voice recordings by the principal researcher to ensure accuracy. Participants were emailed their interview transcripts and offered the opportunity to make any amendments, a step that helped to further enhance the validity of the research method ${ }^{(18)}$.

Prior to analysis audio files were listened to and interview transcripts were read and re-read to allow for immersion in the data, a method employed to enhance analysis $^{(19)}$. Following this immersion, data analysis was conducted first to identify emerging policy options for food security expressed by key stakeholders and second to compare and contrast solutions provided with those found within the academic literature. Data were coded into common themes and proposed solutions by stakeholders were examined against literature arising from the systematic literature review and against each other to remove any inconsistencies. Some solutions to food security offered by stakeholders did not provide a defined role for state government, so these were either adapted to clearly outline the role for government or if no role could be identified they were left out. To further contextualise and validate data a collation of main emerging themes and policy options proposed was presented back to participants in a written document. Stakeholders were given the opportunity to provide any further comments or thoughts they had after reading and reflecting on the data. This process of verifying the research findings helped contribute to the study's rigour and reliability ${ }^{(20)}$.

\section{Results}

Proposed policy options arising from the current research have been organised into four categories of action: (i) policy to create supportive environments; (ii) policy to strengthen community action; (iii) policy to support individual food security; and (iv) policy to improve coordination and capacity for food security. This is consistent with thinking about food security from a macro (supportive environments), meso (community action) and micro (individual) level ${ }^{(21)}$. It also shows consistency with McCullum's three stages of food systems redesign for food security by considering initial food systems change (individual), food systems in transition (community) and food systems redesign for sustainability (structural/ environment changes) ${ }^{(22)}$. Figure 1 provides an overview of these four categories into which policy options are organised and illustrates how policy options move from 


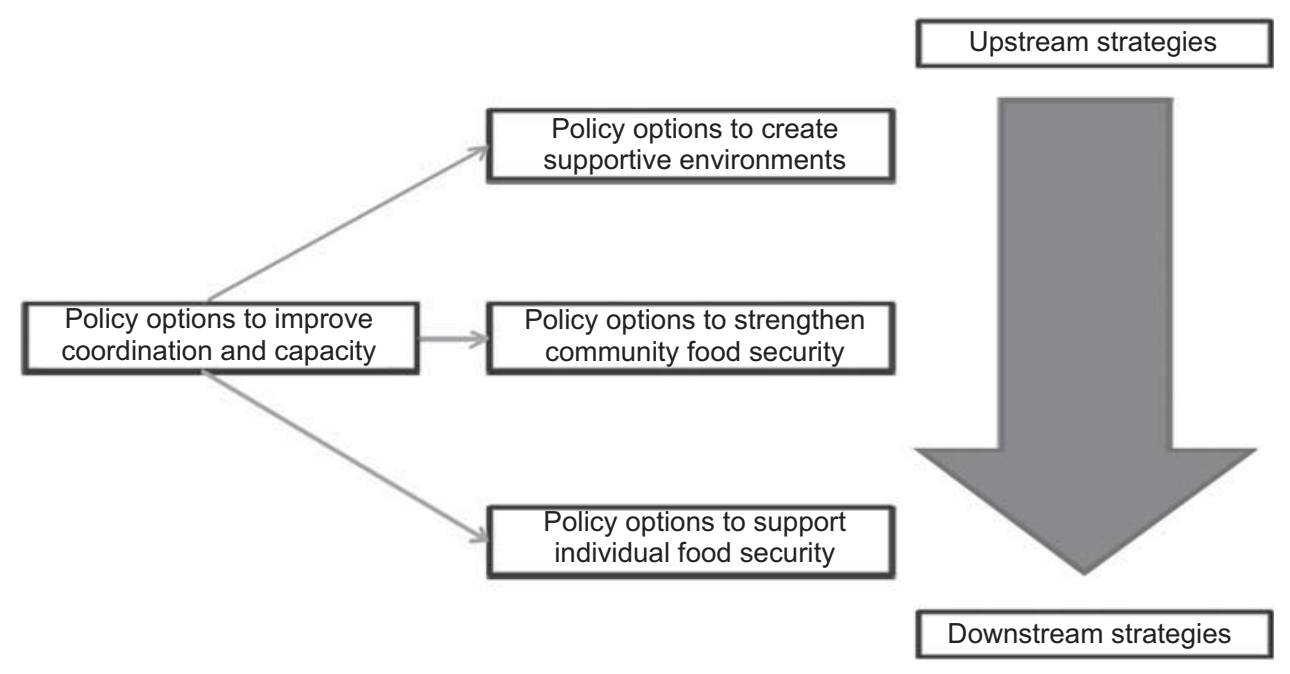

Fig. 1 Policy options categorised as upstream to downstream public health action

those taking an upstream approach through to those taking a more downstream approach. By organising policy options in this way, policy makers can easily identify which aspect of food security they are trying to improve and the type of policy tool being used.

Policy options that met strong resistance from stakeholders were removed while those deemed acceptable by the majority were included. Solutions deemed acceptable (given the breadth of stakeholder representation) are policy options that will allow for easier implementation and therefore are the most realistic. It should be highlighted that the concept of realistic is not necessarily the same as the concept of effective. For example, a very effective policy option could be price manipulation of healthy and unhealthy foods by tax reform. However, this solution met resistance by a number of key stakeholders and policy makers, raising questions about how realistic the solution is in this given context.

Table 1 presents forty-four identified policy options arising from the research under the four identified categories of action in Fig. 1. Within Table 1 policy options are further identified as actions relating to: policy development and implementation (Policy), advocacy action (Advocacy), education programmes (Education), new research (Research), organisational change (Org Dev), increasing workforce capacity (Capacity) and direct government investment and funding for new programmes or infrastructure (Funding). Furthermore policy options have been classified into those addressing the following food security aspects: supply of food (Supply), access to food (Access) and overarching systems supports (Support).

\section{Discussion}

The present research reveals how gathering of local evidence can help expand understanding on an issue by providing a range of context-specific and detailed policy solutions. For example, the proposal for state government to invest in infrastructure (such as roads) to ensure food moves from farm gate to consumer in the smoothest and fastest way relates directly to the South Australian context and the problem of large trucks having to take indirect routes due to poor roads or bridges that are too low to pass under. Similarly, the recommendation to support remote Indigenous community stores to create preferredprovider lists for food purchasing in order to keep food costs down (through resultant increased buying power and reduced transportation costs) arises from stakeholders' in-depth knowledge of how community stores currently operate and the barriers they face to providing fresh affordable food.

In the study design literature was not used to influence or limit stakeholder responses. Rather than presenting participants with the evidence base around what can be done to improve food security and asking them to comment on or pick suitable solutions, stakeholders were asked to draw on their own knowledge and experience to offer potential strategies. This acknowledges and values local expert knowledge and resulted in additional ideas and solutions being presented by stakeholders than were found within the literature. However, the influence of academic literature on stakeholders' knowledge and ideas was evident as many of the proposed solutions were also found within the literature. Research evidence often diffuses through multiple channels, such as scientific and professional journals, the mass media and conversations between policy makers and researchers, and contributes to a series of concepts, generalisations and ideas that impact on the types of solutions offered ${ }^{(23)}$. This is evident in the proposed solutions to work with industry to set targets for certain nutrients (salt, saturated fat, energy) and to develop front-of-pack nutrition labelling. Both of these strategies are currently being employed in the UK in 
Table 1 Local evidenced-based policy options to improve food security in South Australia

Action

Aspect

Policy options to create supportive environments

- Develop and implement planning policies for:

O land zoning/land use to protect arable land for food production;

- new housing developments to ensure retail space for food outlets is available within walking distance and housing development density is sufficient to support a range of viable food retail businesses;

0 new and existing parklands, verges, street planter boxes and all green spaces that ensures indigenous and non-indigenous fruit and nut trees and edible fruiting plants are planted as a priority and produce is freely available;

- new housing developments to ensure appropriate public transport infrastructure is available.

- Strategically increase housing density of existing suburbs to an appropriate density to support food retail businesses.

- Work with existing organisations (e.g. Kaurna Cultural Heritage Board) to identify and reinstate appropriate indigenous fruiting species such as Quandongs which were once prolific throughout the Adelaide Plains.

- Advocate to federal health ministers to:

0 set targets for the food industry (including for supermarket home brands) on major nutrients like salt, saturated fat, energy and fibre;

O introduce a standard evidence-based front-of-pack labelling system (including nutrition information, place of food origin, whether it contains GM ingredients and some kind of environmental impact rating) so that people can choose healthier foods.

- Invest in research that looks at:

$\bigcirc$ true cost of living in South Australia $v$. income for individuals receiving welfare payments. This would look at the non-flexible costs of housing, utilities, transport and how much is left over for food $v$. the true cost of eating a healthy diet. Use this information to lobby the federal government for increases in income payments for certain sectors of the population;

- more sustainable and less resource-intensive farming methods for South Australia.

- Invest in:

$\bigcirc$ infrastructure (such as roads) to ensure foods can move from the farm gate to the consumer in the smoothest and fastest way;

- purchase of food retail spaces so that local council, as the landlord, can decide what type of food business moves into the retail space;

retrofitting existing suburbs with food retail outlet spaces;

- new public transport infrastructure to provide greater flexibility in public transport routes ensuring all suburbs are well connected;

- retrofitting existing public housing facilities (where possible) to ensure adequate food preparation and storage facilities are available including access to fridges.

- Offset high running costs of remote Indigenous community stores such as electricity and the transportation of fresh food to enable food to be sold at the same cost in these stores as it is in urban areas.

- Create more education and employment opportunities to increase people's ability to improve their income (e.g. 'work for the dole' type programmes and training courses).

- Provide investment to an external national organisation (e.g. National Heart Foundation) to work in voluntary partnerships with the food industry on targets for salt, saturated fat, energy and fibre.

- Offer education opportunities for farmers to help them transition to sustainable production methods (e.g. organic farming and polyculture rotated crops) through TAFE courses, current agricultural courses at Urrbrae and Adelaide University.

- Offer training and education on cold chain management practices to ensure better coordination and operations.

Policy options to strengthen community food security

- Invest in research of community-supported agriculture, urban agriculture and other local food initiatives to determine their relevance and application in the South Australian context.

- Provide support to shorten food supply chains by working with local governments on direct retail opportunities (e.g. farmers' markets, farm gate sales, community-supported agriculture).

- Support remote Indigenous community stores to create preferred-provider lists for food purchasing to keep food costs down by resultant increased buying power and reduced transportation costs.

- Offer a small grants scheme to support groups to establish community gardens and promote participation in existing ones.

- Provide financial (and other) support to suitable non-government organisations to assist in capturing and redistributing surplus food.

- Provide appropriate hard infrastructure, intelligence and incentives to ensure an efficient food scrap collection and composting service.

- Provide funding and support for the non-government food welfare sector and encourage providers to link individuals into food growing and sharing community-based programmes.

- Provide required infrastructure and information to support food growing in remote Indigenous communities.

$\begin{array}{ll}\begin{array}{l}\text { Policy } \\ \text { Policy }\end{array} & \begin{array}{l}\text { Supply } \\ \text { Access }\end{array} \\ \text { Policy } & \text { Supply } \\ & \\ \text { Policy } & \text { Access } \\ \text { Policy } & \text { Supply } \\ \text { Policy } & \text { Supply }\end{array}$

$\begin{array}{ll}\text { Advocacy } & \text { Supply } \\ \text { Advocacy } & \text { Supply }\end{array}$

Research Access

Research

Supply

Funding

Supply

Funding

Supply

Funding

Supply

Funding

Access

Funding

Access

Funding

Supply

Funding

Access

Funding

Supply

Education

Supply

Education

Supply

Research

Supply

Org Dev

Supply

Org Dev

Supply

Funding

Supply

Funding

Supply

Funding

Supply

Funding

Access

Funding

Supply 


\begin{tabular}{|c|c|c|}
\hline & Action & Aspect \\
\hline $\begin{array}{l}\text { - Invest in training local people (in customer service, store management and nutrition) to work in remote } \\
\text { Indigenous community stores to reduce employment costs. }\end{array}$ & Education & Supply \\
\hline $\begin{array}{l}\text { Policy options to support individual food security } \\
\text { - Develop home garden design guidelines in consultation with organic home gardeners in South } \\
\text { Australian local councils. }\end{array}$ & Policy & Supply \\
\hline $\begin{array}{l}\text { - Offer free or subsidised seedlings and information on gardening to support individuals to establish } \\
\text { home gardens. }\end{array}$ & Education & Supply \\
\hline $\begin{array}{l}\text { - Provide funding and support to resource community education in community settings to increase } \\
\text { literacy on nutrition and how to access fresh produce (e.g. community centres/non-government } \\
\text { organisations, provide cooking, financial literacy and gardening skills development programmes). }\end{array}$ & Funding & Access \\
\hline $\begin{array}{l}\text { - Sustain the current projects in schools (to ensure healthy weight and nutrition remain high on the } \\
\text { agenda) plus incorporate environmental sustainability and food growing so children consider } \\
\text { environmental issues from an early age, are aware of where food comes from and have a greater } \\
\text { understanding and connection to food growing. }\end{array}$ & Education & Access \\
\hline \multicolumn{3}{|l|}{ Policy options to improve coordination and capacity } \\
\hline $\begin{array}{l}\text { - Create a cross-coordinated whole-of-government food policy that considers agricultural production, } \\
\text { economic development, environmental impacts of food systems, land-use policies, urban planning, } \\
\text { public transport infrastructure and the ability for all South Australians to afford a healthy diet and } \\
\text { participate in food sovereignty. }\end{array}$ & Policy & Support \\
\hline $\begin{array}{l}\text { - Create a food security framework so various key stakeholders can clearly identify their role in } \\
\text { improving food security in South Australia. }\end{array}$ & Policy & Support \\
\hline - Set clear goals and targets for improved food security in South Australia. & Policy & Support \\
\hline - Set clear food security indicators and monitor these to determine changes. & Policy & Support \\
\hline - Invest in evidence generation so strategies are evidence based. & Research & Support \\
\hline $\begin{array}{l}\text { - Provide additional resources to increase the number of Aboriginal Nutrition and Health Workers } \\
\text { around the state. }\end{array}$ & Capacity & Support \\
\hline $\begin{array}{l}\text { - Employ more people within the Department of Primary Industries and Resources of South Australia } \\
\text { who have expertise in sustainable production methods such as organic farming. }\end{array}$ & Capacity & Support \\
\hline $\begin{array}{l}\text { - Employ nutritionist/s within the Department of Primary Industries and Resources of South Australia to } \\
\text { help break down barriers between agriculture and health. }\end{array}$ & Capacity & Support \\
\hline - Invest in employment of food security project officers within agencies such as the local council. & Capacity & Support \\
\hline $\begin{array}{l}\text { - Increase awareness of the environmental impacts of food production and consumption and educate } \\
\text { people about food security in South Australia through targeted campaigns on television, newspapers } \\
\text { and radio. }\end{array}$ & Education & Support \\
\hline
\end{tabular}

their public health nutrition efforts to improve the food supply and change consumer behaviours ${ }^{(24,25)}$.

The method of consultation employed in the present study has a number of advantages. Stakeholders could speak freely during interviews and each had equal opportunity and time to present their views on food security. Discussions were not dominated by a vocal few, as can often occur in focus groups or meetings where there are differential levels of power between participants due to various feelings of confidence, knowledge and experience. Furthermore, stakeholder views were not influenced or persuaded by other participants' views. However this could also be considered a disadvantage as there was no opportunity for stakeholders to discuss concepts and come to agreement on main themes and policy options. Proposed solutions emerging from interviews were raised in subsequent stakeholder interviews to further understand how these solutions could be practically implemented, allowing for further contextualisation.

A limitation of the project was representativeness of participants. Half of the project participants worked either directly or indirectly on issues of food security for a range of local government, community health and peak nongovernment organisations. The remainder of participants worked in health, planning and social policy, or were involved in the food supply across food retailing, food transport, farming and food production sectors. There was a general under-representation of private industry stakeholders across all areas of the food supply and gaps in stakeholders directly involved in public housing and employment. Despite these gaps, use of consultation within the present research effectively captured a diverse range of views from relevant stakeholders.

The process enabled new stakeholders to be identified, information and views to be exchanged and proposed policy solutions to be contextualised, illustrating how gathering local evidence can help expand understanding on an issue. While the research's intent was to develop policy options specifically for the South Australian government and context, many of the policy options are relevant for other settings and indeed some of them have been used in other settings. Furthermore, the principles of the process used to generate these policy options are applicable to other public health problems and other contexts. 


\section{Acknowledgements}

There was no funding received for this research and the authors have no conflicts of interest to declare. The research formed part of the principal author's (A.B.) Dr.PH thesis, which the second author (J.C.) supervised. A.B. conducted the research, including gaining ethics approval and conducting interviews, literature reviews and data analysis. J.C. supervised this process and reviewed the written article, adding comments and suggestions. The authors acknowledge and thank the key stakeholders interviewed for their time and ideas.

\section{References}

1. Rychetnik L, Webb K, Story L et al. (2003) Food Security Options Paper: A Planning Framework and Menu of Options for Policy and Practice Interventions. Sydney: NSW Centre for Public Health Nutrition.

2. Sullivan AF, Clark S, Pallin DJ et al. (2010) Food security, health, and medication expenditures of emergency department patients. J Emerg Med 38, 524-528.

3. Martin KS \& Ferris AM (2007) Food insecurity and gender are risk factors for obesity. J Nutr Educ Behav 39, 31-36.

4. Dinour LM, Bergen D \& Yeh M-C (2007) The food insecurity-obesity paradox: a review of the literature and the role food stamps may play. J Am Diet Assoc 107, 1952-1961.

5. Dubois L, Farmer A, Girard M et al. (2006) Family food insufficiency is related to overweight among preschoolers. Soc Sci Med 63, 1503-1516.

6. Dunifon R \& Kowaleski-Jones L (2003) The influences of participation in the National School Lunch Program and food insecurity on child well-being. Soc Serv Rev 77, 72-92.

7. Whitaker R, Phillips S \& Orzol S (2006) Food insecurity and the risks of depression and anxiety in mothers and behavior problems in their preschool-aged children. Pediatrics 118, 1242-1243.

8. Winicki J \& Jemison K (2003) Food insecurity and hunger in the kindergarten classroom: its effect on learning and growth. Contemp Econ Policy 21, 145-157.
9. Taras H (2005) Nutrition and student performance at school. J Sch Health 75, 199-213.

10. Carter P \& Taylor A (2007) Food insecurity in South Australia. Public Health Bull 4, 23-25.

11. Booth S \& Smith A (2001) Food security and poverty in Australia - challenges for dietitians. Aust J Nutr Diet 58, 150-156.

12. Pawson R (2001) Evidence Based Policy: II. The Promise of 'Realist Synthesis'. http://www.sociology.leeds.ac.uk/ about/staff/pawson.php (accessed November 2010).

13. Hector D, Hyde A, Worgan R et al. (2008) Research evidence can successfully inform policy and practice: insights from the development of the NSW Health Breastfeeding Policy. NSW Public Health Bull 19, 138-142.

14. Blas E, Gilson L, Kelly MP et al. (2008) Addressing social determinants of health inequities: what can the state and civil society do? Lancet 372, 1684-1689.

15. Popay J \& Williams G (1996) Public health research and lay knowledge. Soc Sci Med 42, 759-768.

16. Grey D (2004) Doing Research in the Real World. London: Sage Publications.

17. Patton M (2002) Qualitative Research and Evaluation Methods, 3rd ed. Thousand Oaks, CA: Sage Publications.

18. Perry C (1998) Processes of a case study methodology for postgraduate research in marketing. Eur J Mark 32, 785-802.

19. Green J, Willis E, Hughes R et al. (2007) Generating the best evidence from qualitative research: the role of data analysis. Aust N Z J Public Health 31, 545-550.

20. Morse J, Barret M, Mayan K et al. (2002) Verification strategies for establishing reliability and validity in qualitative research. Int J Qual Methods 1, issue 2, 2.

21. Naidoo J \& Wills J (2005) Public Health and Health Promotion, Developing Practice, 2nd ed. London: Bailliere Tindall.

22. McCullum C, Desjardins E, Kraak V et al. (2005) Evidencebased strategies to build community food security. $\mathrm{J} \mathrm{Am}$ Diet Assoc 105, 278-283.

23. Short S (1998) Elective affinities: research and health policy development. In: Health Policy in Australia, pp. 65-82. [H Garner, editor]. Melbourne: Oxford University Press.

24. Food Standards Agency (2011) Front of Pack Labelling Research. http://www.food.gov.uk/scotland/scotnut/ signposting/devfop/siognpostlabelresearch (accessed October 2011)

25. Food Standards Agency (2008) Saturated Fat and Energy Intake Programme. http://www.food.gov.uk/news/pressreleases/2008/ feb/satfatprog/ (accessed October 2011). 